\title{
The effects of logo frame design on brand extensions
}

\author{
Yu-Shan Athena Chen \\ Department of Industrial Design, Eindhoven University of Technology, Eindhoven, The Netherlands, and \\ Lien-Ti Bei \\ Department of Business Administration, National Chengchi University, Taipei, Taiwan
}

\begin{abstract}
Purpose - The purposes of two experiments were to examine how brands may create a broad brand impression and benefit brand extensions by crafting logo frames.

Design/methodology/approach - Two experimental studies were conducted. Study 1 examines how removing and breaking logo frames expands perceived brand breadth. Study 2 considers the implication of this logo frame effect and indicates the impact of logo frames on brand extension scenarios.

Findings - Removing and breaking logo frames could expand perceived brand breadth and, in turn, benefits the brand extensions, especially for promotion-focused consumers. However, prevention-focused people held favorable brand extension attitudes when the brand logo constructs a complete frame due to its perceived trustworthiness.

Research limitations/implications - As an initial exploration, this study conceptualizes and manipulates logo frames as full framed, partial framed and open logo. Future research studies could include further design features in the examination.

Practical implications - If a brand seeks to be broad, removing or breaking its logo frame is an alternative. However, consequential negative impressions on brand extension attitudes among prevention-focused customers should be considered.

Originality/value - This study is the first investigation into the impacts of logo frame patterns on consumers' perception of brand breadth and the consequent extension attitudes.
\end{abstract}

Keywords Brand image, Brand extension, Regulatory focus, Logo design, Logo frame

Paper type Research paper

\section{Introduction}

The logo frame (i.e. logo with or without outline) is one of the most design features in logo design (Bresciani and Paolo, 2017). In Citroën's logo design history, to take one branding example, the double chevron was embedded into an oval frame in its first iteration but was then later removed from the frame in 1959. Citroën's current emblem, introduced in 2009, is silver with black shades and with the frame removed. Cadillac had a framed logo in 1995 and changed it into an incompletely framed logo in 2014. The incompletely framed logo was further moved in 2014. Such logo frame revisions could also be found in Dodge, Lexus and Volvo.

One case especially attracted our attention: Starbucks' renewal of its logo. In January 2011, Starbucks removed the circle surrounding the Siren and dropped the words "Starbucks coffee." Coinciding with the launch of its new logo, the coffee giant announced:

We've given the Siren a small but meaningful update to ensure that the Starbucks brand continues to embrace our heritage in ways that are true to

The current issue and full text archive of this journal is available on Emerald Insight at: https://www.emerald.com/insight/1061-0421.htm

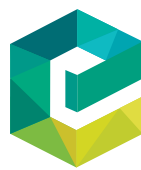

Journal of Product \& Brand Management

29/1 (2020) 97-113

Emerald Publishing Limited [ISSN 1061-0421]

[DOI 10.1108/JPBM-12-2017-1698] our core values and that also ensure we remain relevant and poised for future growth [...] We made this change to support our strategic and business decisions (Kavilanz, 2011).

While Starbucks did not obviously offer any detail at that moment, it soon expanded its juice, bakery and tea business by acquiring Evolution Fresh (Cannold, 2011; Isidore, 2012), Bay Bread (Tadena, 2012) and Teavana Tea (Fox, 2012). Starbucks' new unframed logo was then applied to its new noncoffee products. Starbucks' logo renewal and brand extension strategy inspired our research interest in whether removing or

(C) Yu-Shan Athena Chen and Lien-Ti Bei. Published by Emerald Publishing Limited. This article is published under the Creative Commons Attribution (CC BY 4.0) licence. Anyone may reproduce, distribute, translate and create derivative works of this article (for both commercial and non-commercial purposes), subject to full attribution to the original publication and authors. The full terms of this licence may be seen at http://creativecommons.org/licences/by/4.0/legalcode

The authors sincerely appreciate Ministry of Science and Technology, Taiwan for research funding (Grant No. MOST 104-2410-H-004-128), as well as brandsoftheworld.com and logologo.com provided the logo elements in creating our stimuli in Study 1.

Received 8 December 2017

Revised 24 May 2018

26 August 2018

17 February 2019

16 May 2019

Accepted 23 May 2019 
adding the logo frame impacts consumers' acceptability of brand extension.

Research indicated that a logo frame was tied to the meaning of structure, trustworthiness and protection; but it could also lead to a sense of confinement (Fajardo et al., 2016; Cutright, 2012), depending on a consumer's need for safety. A high need for safety, e.g. a lack of personal control in Cutright (2012) or a high perceived risk in Fajardo et al. (2016), directed consumers to associate a logo frame with a sense of structure and protection. In contrast, when consumers had a low need for safety, a sense of confinement was generated. The pursuit of safety (as opposed to nutrition) coincided with one's prevention focus (as opposed to promotion focus) in a selfregulation system (Higgins, 1997). Consumers' regulatory focus was also observed to moderate if brands with complete typeface logos were perceived to be more trustworthy but less innovative than those with incomplete ones (Hagtvedt, 2011). Therefore, a consumer's regulatory focus is included in the current study to reveal individual differences with respect to the reaction to the logo frame effect.

Based on the above concerns, two studies were conducted. Study 1 examined logo frames' effects on the perceived brand breadth. The brand impression based on the presence of a logo frame was illustrated as the mechanism of this effect. Consumers' regulatory focus was also included to reveal their individual differences. The brand breadth in Study 1 formed the foundation of brand extension. Building on the findings of the first study, Study 2 examined logo frames' influences on brand extension attitudes along with the differences in consumers' regulatory focus. The logo frame effect on brand breadth shall provide managerial insights for logo design on brand extension strategies.

\section{Theoretical background}

Based on the purposes of this study, we first reviewed the design of logo frames, and then the influence of visual closeness vs openness on the breadth of consideration sets. The regulatory focus effect was then introduced as a moderator, as inspired by Hagtvedt (2011) and Fajardo et al. (2016).

\section{Logo design}

Brand logos are complex stimuli composed of multiple visual features through which the meaning of a brand is communicated. Extant branding literature has touched upon examining logo designs and their consequences. The investigated features were shape (circular vs angular, Jiang et al., 2016; square vs strip, Zhong et al., 2018), color (colored vs black, Bresciani and Paolo, 2017; Hynes, 2009; Jin, Yoon and Lee, 2019), typeface (complete vs incomplete, Hagtvedt, 2011), outline (with vs without, Fajardo et al., 2016) and blankness (with vs without white space, Sharma and Varki, 2018). Furthermore, Henderson and Cote (1998) set a milestone in identifying the higher-level design principles that could affect consumer responses. Following their work, scholars continue examining the consequences of logo complexity (van Grinsven and Das, 2016), proportion (Narelle et al., 2007), symmetry (Luffarelli et al., 2019), stability (Rahinel and Nelson, 2016), force (Baxter and Ilicic, 2018), naturalness (Machado et al., 2015) and animation (Brasel and
Hagtvedt, 2016). For example, Foroudi, Melewar and Gupta (2014) indicated that logo design and typeface could influence the recognizability and familiarity of the logo, and further enhance the corporate image. Specifically, Bresciani and Paolo (2017) noted that one-fifth of consumers used an outline, frame or colored background to distinguish logos. Despite its salience, the effect of the logo frame on brand perception has rarely been investigated.

\section{Logo frame design}

There are in effect an infinite variety of possible patterns for a logo frame; broadly speaking, a logo frame pattern can be divided into three types of pattern, namely: the completely framed (i.e. with a complete frame), incompletely framed (i.e. with parts of the frame blanked out) or open (i.e. without a frame at all).

Research has acknowledged that visual closure is associated with confinement. Meyers-Levy and Zhu (2007) focused on ceiling height and found that a relatively low ceiling (eight-foot ceiling) activated a sense of confinement. However, a high ceiling (ten-foot ceiling) could remove such confinement and activate a sense of freedom. The former case of the low ceiling also corresponded to a closed visual image as, for instance, in a framed logo design. This sense of confinement itself led to "an item-specific process," namely, a mental operation whereby the viewer entails the encoding of the context-specific details possessed by each individual item. In the latter situation, the high ceiling corresponded to an open visual image and encouraged what can be called "relational elaboration." Relational elaboration entails association with multiple individual items in a liberal and uninhibited fashion so that the commonalities or abstract concepts shared among the items could be identified and grouped easily (Einstein and Hunt, 1980; Meyers-Levy, 1991). In other words, opening up the visual image leads to relational elaboration, and thereby, generates more connections between unrelated items, while the closed visual image induces a sense of confinement that correspondingly leads to item-specific process, and therefore, generates limited associations between items. Paralleling this study, Fajardo et al. (2016) also found that a logo frame was tied to confinement and removing the visual closure of a logo frame had similar freedom effects found in Meyers-Levy and Zhu (2007). In the present study, the removal or breaking up of logo frames are expected to encourage relational elaboration and activate greater item diversity, whereas framed logos should be related to confinement and activate smaller item diversity, as discussed in the next section.

\section{Logo frame effects on the perceived brand breadth}

Brand breadth refers to the product variability represented by a brand name (Boush and Loken, 1991). For example, Miele, which offers diverse kitchenwares and appliances, has a broad brand breadth, whereas Zwilling focuses on being an excellent knife manufacturer and has a narrow brand breadth. Literature has showed that consumers are more likely to accept a far brand extensions from a brand with broad than narrow brand breadth (Sheinin and Schmitt, 1994; Wu and Yen, 2007). Accordingly, the first research question here would be "whether removing or breaking logo frames could expand the perceived brand breadth". 
As mentioned previously, removing the visual closure could induce a sense of freedom (Fajardo et al., 2016; Meyers-Levy and Zhu, 2007), which might expand the perception of what products a brand could offer. In addition, using Meyers-Levy and Zhu's (2007) findings concerning high and low ceiling heights, we can posit that the open logo may engage individuals in a relational elaboration, while the framed logo (either a complete or incomplete frame) may engage individuals in itemspecific elaborations. The relational elaboration fosters "the abstraction of similarities" (Einstein and Hunt, 1980; MeyersLevy, 1991), which may enable individuals to integrate diverse products under a brand. Finally, Huttenlocher et al. (1991) demonstrated that either a visible boundary on a map or a conceptual category in one's mind indicated a space or category for uniform connectedness, which tended to be perceived as a discrete unit. People who perceived items inside a unit are similar and closer to each other in their perceptions. Therefore, a logo frame may be reminiscent of a portfolio of similar products under a brand. Together, removing the complete or incomplete frame from a logo would enlarge the perceived brand breadth. Using the product portfolio diversity as a proxy for the perceived brand breadth, two hypotheses can be offered:

H1a. A brand with an open logo is associated with greater product portfolio diversity than one with a completely framed logo.

H1b. A brand with an open logo is associated with greater product portfolio diversity than one with an incompletely framed logo.

Based on Hagtvedt's (2011) findings, which demonstrated that incomplete patterns implied innovativeness and increased the level of interest toward the brands, consumers with a high perception of innovativeness were likely to accept new products under the brand (Dotzel et al., 2013). Another relevant work by Luffarelli et al. (2019) indicated that asymmetrical logos tended to be perceived as more exciting than symmetrical logos. Their measurements of exciting included daring and imaginative, which were similar to innovativeness as in Hagtvedt (2011). Although incompletely framed logos are not always asymmetrical, they are likely to be asymmetrical inherently. Therefore, the current study suggests that breaking the logo frames (i.e. comparing the effects of an incompletely framed vs a completely framed logo) may increase the perception of innovativeness and then expand the perceived brand breadth. This prediction is stated as follows:

H1c. A brand with an incompletely framed logo is associated with greater product portfolio diversity than one with a completely framed logo.

\section{The mediating role of brand impression}

As mentioned previously, a logo frame may induce a sense of confinement, while removing the frame may generate a sense of freedom (Fajardo et al., 2016; Meyers-Levy and Zhu, 2007). To further detect the consequential perception associated with removing and breaking a logo frame, white space, a particular rhetorical device or visual trope common to designing, was introduced. Two types of white space are commonly used by designers, one is the conspicuous space around a design found in the natural space between words and letters (i.e. a passive white space) and the other is the space between the individual design elements (i.e. an active white space; see the graphic illustration in Sharma and Varki, 2018, p. 271). Designers, especially minimalists, will intentionally leave part of the art blank to convey the sense of cleanliness and modern affluence (Müller et al., 2013). In particular, a passive white space is tied to a brand's prestige, market power, brand trustworthiness and leadership in the industry (Pracejus et al., 2006). Paul Rand's famously minimal IBM block logo in the late 1950s is a classic example (Meggs and Purvis, 2011). A progressive trend toward adding active white space to a brand logo ensued to improve the visual clarity of a design's structure (Turnbull, 2011; Sharma and Varki, 2018). Hagtvedt (2011) noted that compared to Paul Rand's original design, the incompetentness of his renewal IBM logo (using white stripes on characters to add active white space) creates a perceptual ambiguity and, in turn, contributes to the high innovation but low trustworthiness impression.

In the context of this research, removing the logo frame could be seen as adding passive white space to a logo (around the design). Pracejus et al. (2006) indicated that market power and leadership in the industry were associated with passive white space. Along this line, it is proposed that open logos may enhance the brand image of leadership more than framed logos (either with a complete or an incomplete frame). Following the works of Meyers-Levy and Zhu (2007) and Fajardo et al. (2016), removing (vs retaining) the logo frame may enhance a sense of freedom. The brand impression of leadership and freedom may further mediate the effect of removing logo frames on the perception of brand breadth:

H2a. The brand impression of leadership and freedom mediates the effect that an open logo (with more passive white space) associated with greater product portfolio diversity than a completely framed logo.

$H 2 b$. The brand impression of leadership and freedom mediates the effect that an open logo (with more passive white space) associated with greater product portfolio diversity than an incompletely framed logo.

Breaking the logo frame (where parts of the frame are left blank) could be considered as adding active white space to the logo (blanks between frame fragments), which involves high brand innovation (Hagtvedt, 2011). Accordingly, breaking logo frames is expected to increase brand innovation and in turn enlarge the peried brand breadth:

H2c. The brand impression of innovation mediates the effect that an incompletely framed logo (with more active white space) associated with greater product portfolio diversity than a completely framed logo.

Although Hagtvedt (2011) also noted that incompleteness could lower trustworthiness, it is worth noting that the brand impression of trustworthiness was not proposed in any hypothesis above due to its complicated effects. Removing the logo frame to add passive white space might 
increase the sense of brand trustworthiness (Pracejus et al., 2006). However, both Cutright (2012) and Fajardo et al. (2016) pointed out that framed objects would be more favorable when people perceived chaos or risk. Their study implied that the perception of trustworthiness with logo frame patterns varied by individual characteristics. Therefore, the effect of brand trustworthiness will be further discussed in Study 2.

\section{The moderating role of regulatory focus in forming brand breadth perception}

Although research has shown that a similar extension of a brand is more favorable than a dissimilar one (Aaker and Keller, 1990), Yeo and Park (2006) indicated that the positive effect of a similar extension was only revealed on prevention-focused consumers but not promotion-focused ones. It is, thus, reasonable to propose that regulatory focus could be related to the effect of logo frames on brand extension.

Regulatory focus theory (Higgins, 1997, 2012b) denotes two coexisting regulatory focus systems, promotion and prevention focus, motivating people's decisions and actions. The promotion system regulates nurturance needs and is concerned with growth, advancement and accomplishment. People with a strong promotion focus strive toward ideals, desires and aspirations. To strive for these goals, promotion-focused people tend to explore and search for possible alternatives to achieve their goals. In contrast, the prevention system regulates security needs. Individuals with a strong prevention focus care about safety and responsibility. Prevention-focused people concentrate on avoiding mismatches to these goals, and they thus, tend to select options only after a prudent consideration of details (Aaker and Lee, 2006; Higgins et al., 2003). As prevention-focused people tend to weigh risk more than promotion-focused people, they prefer similar brand extensions more than promotion-focused ones (Yeo and Park, 2006).

Two studies, Cutright (2012) and Fajardo et al. (2016), signal the possibility that regulatory focus may be related to the effect of logo frames. Cutright (2012) studied the effect of visual boundaries and found that individuals preferred bounded objects to unbounded ones when they sensed chaos. Cutright reasoned the underlying mechanism was that presenting the frame generated the sense of structure and order, which eased the threat to personal control. Thus, the need for control was similar to the motivations of a prevention focus.

Fajardo et al. (2016) provided another case in which logo frames were associated with protection or confinement under high or low risk, respectively. Participants were primed to be under low (high) risk by listing things, which made them feel safe or unsafe. After the priming task, they reviewed an advertisement in which a fictitious brand, having a completely framed or an open logo, launched a new product and rated their purchase intention. The results indicated that logo frames increased purchase intention under a high-risk mentality, where the sense of protection generated by the logo frames acted as a mediator. However, participants with a low-risk mentality associated logo frames with confinement, which could further decrease their purchase intention. These findings demonstrated that people's associations with protection or confinement depended on their high or low-risk mentality, respectively. Consumers who were under a high or low threat or risk had a high or low need for safety, which paralleled with the concept of a prevention or promotion focus.

The findings of Cutright (2012) and Fajardo et al. (2016) may be interpreted as follows: consumers associate a frame with a sense of structure and protection under a prevention focus but associate a frame with a sense of confinement under a promotion focus. Hagtvedt's (2011) logo typeface study was comparable to the findings of Cutright (2012) and Fajardo et al. (2016). Hagtvedt asked participants to think about a negative or positive outcome and briefly describe the strategies they might use to prevent or promote that outcome. He found that brands with complete typeface logos were perceived to be trustworthy or less innovative when participants focused on prevention or promotion, respectively. Furthermore, Hagtvedt noted that brands with incomplete typeface logos were perceived to be more innovative when participants were promotion focused rather than prevention focused. This result could be analogous to the effects of logo frames and suggests the need to consider the moderating role of a regulatory focus in the current study.

The elaborations that people with different regulatory focuses use to process information regarding brands explain the moderating effects. A promotion or prevention focus engages people in relational and item-specific elaborations, respectively (Lee and Aaker, 2004; Meyers-Levy and Zhu, 2007). Therefore, a promotion focus is expected to enhance the effects of removing the logo frames and expand the perceived brand breadth. An open pattern encourages the usage of relational elaboration, which better fits promotion-focused people's information processing. Removing the logo frames may also encourage prevention-focused people to process information by considering the relationships among a brand's product portfolio, namely, relational elaboration. However, because prevention-focused people are accustomed to item-specific elaboration, the effect of an open logo on broadening the perceived brand breadth would be finite.

Together, consumers' promotion focus is expected to enhance the expansion of perceived brand breadth when the logo frame is removed. Furthermore, a promotion focus would direct people to associate logo frames with confinement, which reduces the perceived brand breadth with the logo frame present. The two forces enable the relative strong impact of frame patterns on promotion-focused people. However, the logo frame is positively associated with protection by prevention-focused consumers. Therefore, the effect of increasing brand breadth by removing the logo frame should not be observable on these prevention-focused consumers. Two hypotheses are proposed:

H3a. Consumers perceive a brand with an open logo to have a greater diversity of product portfolios than with a completely framed logo when they are promotionfocused, whereas such an effect was eliminated when they are prevention-focused.

$H 3 b$. Consumers perceive a brand with an open logo to have a greater diversity of product portfolios than with an incompletely framed logo when they are promotionfocused, whereas such an effect was eliminated when they are prevention-focused. 
As previously mentioned, breaking logo frames could be associated with innovativeness and then increase the perceived brand breadth. Because promotion-focused consumers are oriented to obtaining the potential benefits, they likely emphasize the innovativeness generated by incompletely framed logos more than prevention-focused ones. Consequently, the effect on the perceived brand breadth by breaking a logo frame to make it incomplete should be stronger among promotion- than prevention-focused people. This prediction parallels Hagtvedt's (2011) study in which the promotion focus enhanced the favorable attitudes toward the firm through perceived innovativeness when the firm had an incomplete typeface logo:

H3c. Consumers perceive a brand with an incompletely framed logo to have a greater diversity of product portfolios than with a completely framed logo when they are promotion-focused, whereas such an effect was eliminated when they are prevention-focused.

\section{Study 1. The effects of logo frames on perceived brand breadths}

Study 1 has two folders. The first experiment investigated whether removing or breaking logo frames could enlarge consumers' perceived brand breadth. The moderating role of the regulatory focus was also explored. Participants reviewed the logos and listed the products, which the brands could possibly offer. The product associations with brands were collected to examine the hypothesis with regard to frame patterns, regulatory focus and perceived brand breadth. The second session was conducted to explore the mechanism of brand impressions generated by completely framed, incompletely framed and open logos for perceived brand breadth.

\section{Method of Study 1 \\ Materials}

Fictitious logos were designed for the purpose of this study to control for the possible confounding effect of existing design features and brand preferences. Six sets of completely framed, incompletely framed or open fictitious logos were designed as the stimuli (Appendix 1). To control the color impression (Hynes, 2009), two design experts reviewed and balanced the color chroma and brightness. The six replicates included both abstract and natural designs, four with fictitious brand names and two without brand names to balance the possible interference. Considering that pattern shapes may confound the logo frame effect, this study included both circular and angular logos in the stimuli (Jiang et al., 2016). The only difference in each set of stimuli was whether the logos were completely framed, incompletely framed or open.

\section{Participants and procedure}

In total, 160 undergraduate students (128 women and 32 men) mainly from the local business school, with an average age of 20.99 (SD = 2.30), participated in the experiment in exchange for $€ 2$. They were randomly assigned into three experimental conditions to associate products with six completely framed, incompletely framed or open logos. The six logos were provided to the participants in a random order. Participants reviewed each logo at their leisure and listed all the possible products that the brand may offer. Their product associations were counted and coded to indicate the brand breadth for further analysis. Following the product associations, participants provided the logo preference on a seven-point scale. Then, the regulatory focus was accessed by the ten-item measurement developed by Haws et al. (2010). Finally, the demographic backgrounds were then collected.

Next, participants were invited to participate in another extended task regarding brand impression after a short break. The break sustained participants for another quarter hour after the main product association task. Meanwhile, the break was expected to minimize the demand artifacts for suspiciousness of the relationship between product associations and brand impressions. Ten participants missed the second task because of tiredness or unwillingness. Finally, 150 undergraduate students (119 women and 31 men), with an average age of 20.95 ( $\mathrm{SD}=2.25$ ) remained. Because the gender distribution of participants was unbalanced, all variables were first examined by gender before the hypothesis test.

\section{Brand impression}

To capture the brand impressions associated with the logo frame patterns, we screened the brand image and brand personality literature; we included: honesty, cheerfulness, imaginativeness, excitement, reliability, efficiency, ambition, wisdom and steadiness - impressions from Aaker (1997). We also included friendliness, openness, freedom and fashion, which were impressions from Arora and Stoner (2009). Finally, we added trustworthiness and innovation from Hagtvedt (2011). High-technology and internationalization were also considered to capture the "up-to-date" impression mentioned in Aaker (1997). In addition, we included the high-quality impression, which is critical for forming brand extension attitudes (Reast, 2005; Sichtmann and Diamantopoulos, 2013) and diversification, which is closely relevant to our research target, brand breadth. Participants were also encouraged to provide their thoughts beyond this list.

An exploratory factor analysis was conducted among the associated brand impressions in the checklist. The principal component extraction with a varimax rotation was used to interpret the factor loadings. Three factors were extracted based on the Kaiser criterion (eigenvalues $>1$ ) and the examination of a scree plot. The first factor (eigenvalue $=2.65$ ) included internationalization, high-technology, efficiency, diversification, wisdom, high-quality, innovation and fashion. The first factor was named proficiency and covered both the leadership and innovation impressions proposed in $\mathrm{H} 2 \mathrm{a}-\mathrm{H} 2 \mathrm{c}$. The second factor (eigenvalue $=2.43$ ) was vivacity, which included freedom, excitement, cheerfulness, imaginativeness, intimacy, openness and ambition. The final factor (eigenvalue $=1.87$ ) focused on accountability, which included trustworthiness, reliability, steadiness, honesty and friendliness. The corresponding items were then averaged separately to indicate proficiency, vivacity and accountability.

\section{Regulatory focus}

Following Avnet and Higgins (2006), using a median split of the difference between promotion and prevention scores, participants were divided into promotion- and prevention- 
focused groups. Nine participants who had equal to the median difference scores were excluded from further analysis. Finally, 76 promotion-focused and 75 prevention-focused participants were identified. The promotion-focused participants had higher promotion scores than prevention-focused people did $\left(M=4.31\right.$ vs $\left.3.57, t_{(149)}=12.25, p<0.001\right)$. The preventionfocused participants had higher prevention scores than promotion-focused people did $\left(M=3.51\right.$ vs $3.11, t_{(149)}=7.41$, $p<0.001)$.

\section{Brand breadth}

To illustrate the hypothesis regarding certain frame patterns and the perceived brand breadth, an index of product portfolio diversity was created based on the eight-digit Global Trade Item Number (GTIN-8; GS1, 2016) list, which is a global and multi-sector standard for product categories and identification. This study used GTIN for two reasons. First, the GTIN provides a systematic and standard framework for categorizing products worldwide. Second, the GTIN categorizes the products into four levels of product categories, i.e. product segment, family, class and brick, and from the most general ones to the most specific ones; this enabled us to identify the product's portfolio diversity, namely, the brand breadth in this study. The first code, labeled product segment, is a highly general product category, such as "beauty and personal care." The second code, labeled product family, consists of subcategories under the product segment such as "cosmetics." The third code, labeled product class, consists of the relatively concrete categories under a product family. A "makeup" is a subcategory of the product segment of "cosmetics." The fourth code, labeled product brick, is the specific product item. For example, "lipstick" and "eyeshadow" are the items under the product class of "makeup." A portfolio with greater diversity would be signaled when respondents associated this brand with a product segment (e.g. beauty and personal care) more than when they did with a specific product (e.g. lipstick or eyeshadow) under a brand.

According to the GTIN-8 announced by GS1 (2016), a product segment, family and class consisted of an average of 104.11, 51.84 and 6.89 products, respectively. Therefore, an index was created to represent the product portfolio's diversity based on the above illustration. The product portfolio diversity was indicated by the following formula: $104.11 \times$ segments + $51.84 \times$ families $+6.89 \times$ classes $+1 \times$ bricks, which represented the brand breadth.

\section{Prescreening the data}

Participants generated a total number of 2,787 product associations with the six sets of logo stimuli, with an average of 2.90 items per respondent for each logo. The product associations, which were not covered by the GTIN list were excluded (e.g. Taoist magic figures). The numbers excluded among three frame patterns did not differ $\left(F_{(2,157)}=0.01, n s.\right)$. Finally, a total number of 2,170 valid responses, with an average of 2.26 items for each logo, were included for further analysis. The amount of associations did not differ between male and female participants $\left(M_{\text {male }}=2.12, M_{\text {female }}=2.31\right.$, $t_{(148)}=1.46, n s$. $)$.

\section{Results of Study 1}

\section{Logo preference}

Significant main effects of frame patterns were found among promotion-focused $\left(F_{(2,73)}=6.55, p<0.01\right)$ and preventionfocused participants $\left(F_{(2,72)}=3.93, p<0.05\right)$. The post-hoc tests indicated that promotion-focused participants preferred the open and incompletely framed logos to the completely framed logos (open vs complete frame: $M=3.57$ vs 3.20; $F_{(1,145)}=7.43, p<0.01$; incomplete frame vs complete frame: $M=3.72$ vs $\left.3.20 ; F_{(1,145)}=14.57, p<0.001\right)$. However, prevention-focused participants preferred the completely framed logos to the incompletely framed logos (3.48 vs 3.14 , $\left.F_{(1,145)}=6.27, p<0.05\right)$, and their preferences of completely framed and open logos were similar $\left(F_{(1,145)}=3.21, n s\right.$. $)$.

\section{Brand breadth}

The gender effect was checked in advance, which indicated no significant influence on brand breadth $\left(F_{(1,148)}=13.47, n s.\right)$. Frame patterns exerted significant effects on product portfolio diversity $\left(F_{(2,144)}=13.25, p<0.001\right)$. The planned contrasts indicated that participants associated greater diverse products with open logos than completely framed logos $(M=59.43$ vs $37.17 ; F_{(1,147)}=23.46, p<0.001$ ), which supported $H 1 a$. As $H 1 b$ predicted, a greater diversity of products was associated with open logos than with incompletely framed logos $\left(M=59.43\right.$ vs $\left.45.80 ; F_{(1,147)}=8.30, p<0.01\right)$.

Next, the moderating effects of regulatory focuses were examined. As expected in $\mathrm{H} 3 \mathrm{a}$, participants associated a greater diversity of products with open logos than with completely framed logos, and such enhancement was stronger among promotion- than prevention-focused participants (promotion: $M=73.39$ vs 36.62 , prevention: $M=45.47$ vs $37.73 ; F_{(1,144)}=$ $11.11, p<0.001)$. Promotion-focused participants associated a greater diversity of products with open logos than with incompletely framed $\operatorname{logos}\left(M=73.39\right.$ vs $53.93 ; F_{(1,144)}=$ 10.67, $p<0.001)$. However, such effects were not found among prevention-focused participants $(M=45.47$ vs 37.67 , $\left.F_{(1,144)}=1.52, n s.\right) . H 3 b$ was supported.

As predicted in $H 1 c$, breaking logo frames (complete vs incomplete frame) increased the product portfolio diversity $\left(M=45.80\right.$ vs $\left.37.17 ; F_{(1,147)}=3.85, p=0.05\right)$. The moderating effects of the regulatory focus, namely, $H 3 c$, was likewise supported (promotion: $M=53.93$ vs $36.62, M=37.67$

Figure 1 The product portfolio diversity associated with open, incompletely framed and completely framed logos among all, promotion-focused and prevention-focused participants

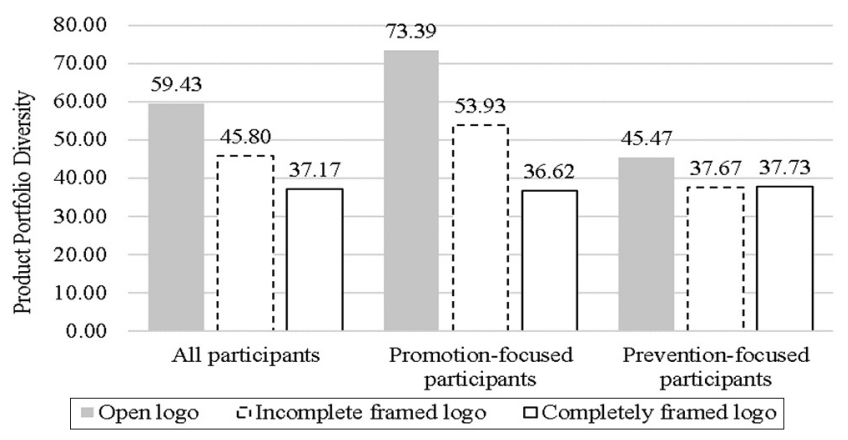


vs $\left.37.73 ; F_{(1,144)}=3.97, p<0.05\right)$. These findings are shown in Figure 1.

\section{Brand impressions}

Yet, while the findings confirmed our main argument, the underlying mechanism needs further investigation. The mediating effects of proficiency (i.e. brand leadership and innovation), vivacity (i.e. freedom) and accountability (i.e. trustworthiness) impressions with the three logo frame patterns on product portfolio diversity were then tested as proposed in $\mathrm{H} 2 \mathrm{a}-\mathrm{H} 2 \mathrm{c}$.

The GLM with six repeated measures revealed that frame patterns exerted significant effects on proficiency, vivacity and accountability (proficiency: $F_{(2,144)}=12.64, p<0.001$; vivacity: $F_{(2,144)}=16.89, p<0.001$; accountability: $F_{(2,144)}=$ $4.69, p<0.05)$. Neither the main effect of a regulatory focus nor its interaction effects with frame patterns on the associated brand impressions were found. The planned contrasts indicated that both incompletely framed $\left(M=0.17 ; F_{(1,147)}=\right.$ $17.99, p<0.001)$ and open $\log 0 \mathrm{~s}\left(M=0.18 ; F_{(1,147)}=20.90\right.$, $p<0.001)$ implied higher proficiency than the framed logos did (vs $M=0.10$ ), which fit with the suggestion of leadership impression by Pracejus et al. (2006). The open logos were also strongly associated with vivacity (i.e. freedom) $\left(M_{\text {open }}=0.21 \mathrm{vs}\right.$ $M_{\text {complete }}=0.11, F_{(1,147)}=34.94, p<0.001 ; M_{\text {open }}=0.21 \mathrm{vs}$ $\left.M_{\text {incomplete }}=0.16, F_{(1,147)}=8.41, p<0.01\right)$. Furthermore, the incompletely framed logos implied a higher brand vivacity than the framed logos did $\left(M_{\text {incomplete }}=0.16\right.$ vs $M_{\text {complete }}=0.11$, $\left.F_{(1,147)}=9.07, p<0.01\right)$. Regarding accountability (i.e. trustworthiness), the completely framed logos implied higher accountability than the incompletely framed $\log$ os $(M=0.19$ vs $\left.0.11 ; F_{(1,147)}=7.86, p<0.01\right)$. Meanwhile, the open logos also had greater accountability than the incompletely framed $\log 0$ ( $M=0.18$ vs $\left.0.11 ; F_{(1,147)}=6.12, p<0.05\right)$, similar to the IBM logo renewal case noted by Hagtvedt (2011). Figure 2 demonstrated the resulting patterns.

\section{The mediating role of brand impressions on brand breadth}

Three mediating models with 2,000 bootstrap estimates were conducted to analyze the effect of frame patterns on average product portfolio diversity while simultaneously including brand proficiency, vivacity and accountability in the model. The models supported a part of the hypothesis $H 2 a$ that vivacity mediated the effect of removing the complete frame from a logo (i.e. open vs complete frame) on the product

Figure 2 The proficiency, vivacity and accountability associations of open, incompletely framed and completely framed logos

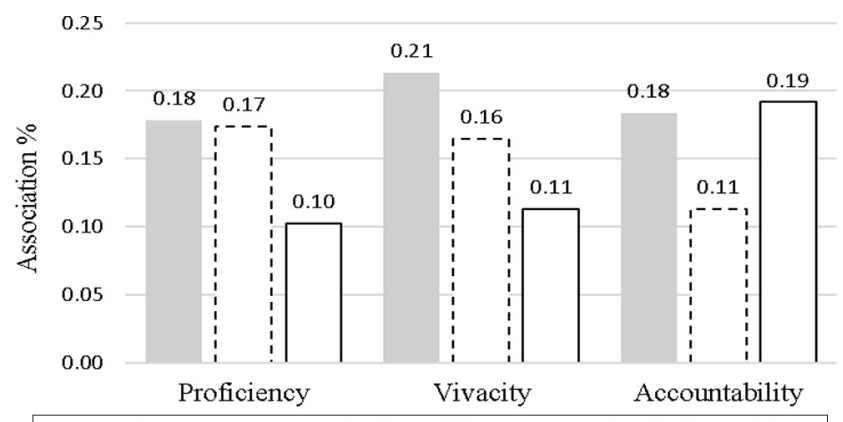

Open logo $\check{L}_{-}$Incompletely framed logo $\square$ Completely framed logo portfolio diversity (mean estimate of relative indirect effect size $(E S)=13.64,95$ per cent $\mathrm{CI}=5.78$ and 23.20). However, the mediating effect of proficiency was not revealed, which did not support the other part of $H 2 a$. As proposed in $H 2 b$, the vivacity mediated the relationship between removing incomplete logo frames (i.e. open vs incomplete frame) and product portfolio diversity $(E S=5.94,95$ per cent $C I=1.13$ and 13.86). The relative direct effects of removing complete and incomplete frames on the product portfolio diversity were not significant (open vs complete frame: $\beta=7.76, t=1.60$, ns.; open vs incomplete frame: $\beta=8.13, t=1.75, n s$.), suggesting a pattern of full mediation of vivacity in the relationship between removing logo frames and product portfolio diversity.

Furthermore, breaking the logo frames (i.e. incomplete frame vs complete frame) enhanced the product portfolio diversity through proficiency $(E S=5.74,95$ per cent $\mathrm{CI}=1.01$ and 12.96). This result was consistent with $\mathrm{H} 2 \mathrm{c}$ because proficiency included the concept of innovation. Meanwhile, the proficiency fully mediated the effect of breaking the logo frames (i.e. incomplete vs complete frame) on the product portfolio diversity $(\beta=5.46, t=1.11, n s$. $)$. As expected, the main effects and mediating effects of accountability were absent from this model. The complicating effect of accountability will be revealed in Study 2. Figure 3 demonstrated the testing results on the mediation roles of vivacity, proficiency, and accountability in the relationship between frame patterns and product portfolio diversity.

\section{Regulatory focus moderates the mediating effects of brand impression}

In line with promotion-focused people's orientation for attaining possible gains, brand vivacity may activate promotion-focused people to broaden the perceived brand breadth rather than prevention-focused people. Drawing on the findings of Hagtvedt (2011), which noted the enhancement of a promotion focus in the relationship between incomplete typeface logos and brand innovativeness perception, the current study expected to find the synchronized effects of promotion focus on perceived brand breadth. While the mediating effect of brand accountability was absent in our model, accountability fits prevention-focused people's concentration of safety and responsibility. Therefore, it was interesting to explore the possible effects of brand accountability on the perceived brand breadth. Together, the moderating role of the regulatory focus was expected in the above mediating models.

Dividing the participants into promotion- and preventionfocused subgroups, two sets of mediating models, each with 2,000 bootstrap estimates, were conducted to analyze the logo frame effects on product portfolio diversity. The models revealed that removing the complete frames from a logo had a direct effect on broad perceptions of brand breadth ( $\beta=18.40$, $t=3.57, p<0.001)$. Such logo modification indirectly enhanced the product portfolio diversity through brand vivacity $(E S=18.75,95$ per cent $C I=8.47$ and 31.38) among the promotion-focused participants. Interestingly, in terms of product portfolio diversity, removing the complete frames (i.e. open vs complete frame) broadened the prevention-focused participants' perception mainly through brand proficiency $(E S=10.48,95$ per cent $\mathrm{CI}=3.01$ and 25.53). 
Figure 3 The mediation roles of proficiency, vivacity and accountability in the relationship between frame patterns and product portfolio diversity, along with the moderating role of the regulatory focus within the mediation mode
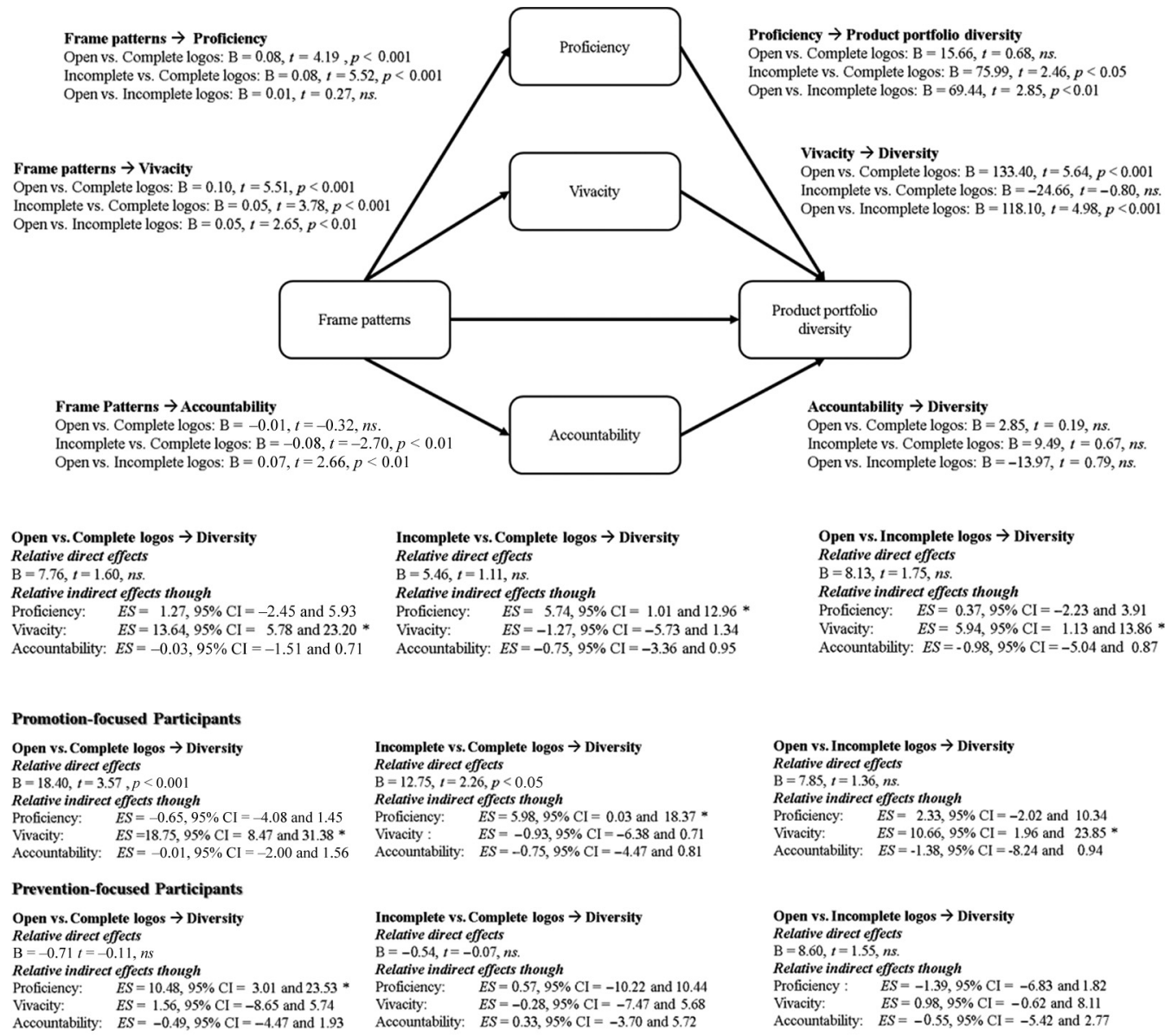

Notes: ES $=$ mean estimate of effect size; ${ }^{*} p<0.05$, according to the exclusion of zero in $95 \%$ confidence intervals after 2,000 bootstrap estimates

\section{Conclusions and discussions of Study 1}

Study 1 supported the hypothesis that consumers associate more diverse products with an open logo than a completely or incompletely framed logo. It suggests a brand with an open logo may have more expansive brand breadth than those with a completely or incompletely framed logo. Breaking the logo frame to create an incomplete frame likewise benefitted the scope of brand perception. The findings demonstrated that consumers may spontaneously generate a perception of product variety with a brand upon first glance at a logo frame.

The brand impression generated by the frame patterns of logos acted as the mediators, as suggested by Meyers-Levy and Zhu (2007). Open logos, which add passive white space, were associated with vivacity more than the incompletely framed ones; while the incompletely framed logos, which add active white space, were associated with vivacity more than the framed logos. Furthermore, the brand's vivacity accounts for the effects of open logos (which implied removing the complete or incomplete frame from a logo) on expanding the perceived brand breadth. Breaking the frames (i.e. comparing complete vs incomplete frames) likewise enhanced the expansive perceived brand breadth; however, the mechanism was the proficiency impression, such as internationalization, hightechnology, diversification and innovation.

Brand accountability held complex results. Both completely framed and open logos were perceived as more accountable than incompletely framed logos. A completely framed logo signaled security and reliability as pointed out by Cutright (2012) and Fajardo et al. (2016). Meanwhile, Pracejus et al. (2006) suggested that adding passive white space (which removing the frame enhances), was associated with market leadership in the industry. Therefore, the incompletely framed logos were the least accountable or trustworthy, as Hagtvedt (2011) warned. However, the accountability did not act like the confinement in MeyersLevy and Zhu (2007), and its mediating effect was not significant in Study 1. These consist and inconsistent results definitely need further investigation.

The logo frame effects on promotion-focused participants were more exaggerated than on prevention-focused ones. Both promotion- and prevention-focused participants associated the brand using a completely framed logo with accountability, an 
incompletely framed logo with proficiency and an open logo with vivacity. However, the mediating roles of these brand impressions on perceived brand breadth depended on consumers' regulatory focus. Promotion-focused people perceived the wide brand breadth due to the brand's vivacity association, whereas prevention-focused people evaluated the brand breadth through the brand's proficiency.

Study 1 makes two main contributions. First, this study initially demonstrates that beyond the focus of a logo's positive aesthetic appeal, brands may use the meaning tied to design features, such as different frame patterns, to incubate corresponding brand impressions. Obviously, an open logo is tied to the meaning of vivacity, referring to freedom, excitement, cheerfulness, imaginativeness, intimacy, openness and ambition, which may be a good alternative to build a brand with the appeal (Aaker, 1997). Furthermore, erecting a complete frame may create accountability with the brand; and an incomplete frame may enhance proficiency but lower brand accountability.

Second, by contrasting existing literature with our results, we have expanded the influence of logo design to brand breadth perception and its different possible elaborations. Previously, researchers mainly focused on studying the impressions and brand/product attitudes generated by design features and dimensions. Study 1 proposes a novel cognitive mechanism: item-specific and relational elaborations. Relational elaboration can be used to exploit the large and diverse product portfolios, which participants associated with an open and incompletely framed logo.

Study 1 provides a foundation to support the proposition that removing and breaking logo frames may benefit the brand extensions because of the broad perceived brand breadth. As the perceived brand breadth is one of the important determinants of a successful brand extension (Sheinin and Schmitt, 1994), Study 2 will directly examine the implication of logo frame effects on brand extension attitudes.

\section{Study 2. The effects of logo frames on attitudes toward brand extensions}

The purpose of Study 2 was to apply what has been found in Study 1 on a brand extension situation. Study 1 was the first step in revealing that an open logo had more expansive brand breadth than an incompletely framed logo, and an incompletely framed logo had a wider brand breadth than a framed logo. Study 2 used the results of brand breadth to examine the acceptance of a brand extension based on the perceived fit of new extensions. To directly investigate consumers' acceptance of a brand extension, the concept of perceived fit should be reviewed first.

\section{Theoretical background of Study 2}

\section{Perceived fit of new brand extension}

The perceived fit of the parent brand and the new extension has been the most emphasized factor of a successful brand extension in previous related research (Buil et al., 2009; Völckner and Sattler, 2006). It was suggested that consumers could transfer the high-quality image of the parent brand to the new extension if the perceived fit was high (Keller and Aaker, 1992).
Early on, the perceived fit was defined as the similarity between the original and new product categories, including their distance, complementarity and substitutability (Aaker and Keller, 1990; Bottomley and Holden, 2001; Boush and Loken, 1991; Dawar, 1996). Park et al. (1991) expanded the concept of perceived fit to two dimensions, namely: product feature similarity and brand concept consistency. The perceived fit is akin to a psychological distance between the parent brand and the new extension. A high degree of fit implies psychological proximity and consumers can easily accept the new extension.

Logo frame effects on the perceived fit of brand extension Drawing upon findings in social cognition research, the labeling of ingroup and outgroup members would lead to illusory and exaggerated social distances between groups (Wilder, 1986). In the case of social distance, the "distance" is not literally spatial, but a metaphor for intimacy. Similarly, far vs near extensions are a metaphor for indicating product similarity between the parent brand and the new product.

A logo frame, by its nature as having a boundary, highlights the inside and outside members. A logo frame erects the mental boundary of a brand, which indicates products within and beyond a parent brand. Consumers may illusively overestimate the "distance" between a parent brand and its new extension, and consider the new extension being poorly fit with the parent brand. Thus, logo frames would disadvantage the brand extension attitudes.

Adding white space to a logo increased design cleanliness and visual balance (Pracejus et al., 2006), which improved the perceptual fluency due to the ease of visual processing among design features. Sharma and Varki (2018) showed that perceptual fluency could spill over to consumers' attitudes toward a brand. Thus, the halo or spillover effect by removing logo frames and adding white space to a logo design (i.e. removing a complete or an incomplete frame to be an open logo) may also positively impact consumers' attitudes toward the brand's new extension. Together, consumers may favor the extensions with open logos than those with completely or incompletely framed logos in terms of large perceived brand breadth and brand extension fit:

H4a. Consumers' attitudes toward the brand extension by open logos are superior to complete framed logos.

H4b. Consumers' attitudes toward the brand extension by open logos are superior to incomplete framed logos.

Meyvis and Janiszewski (2004) demonstrated that consumers could easily access the core benefits of a narrow brand and these benefit associations (e.g. brand positioning) would favor the brand extension attitudes. These findings can apply to the brand extension scenarios of Miele and Zwilling. The work of Meyvis and Janiszewski (2004) implies that Zwilling has a limited advantage over Miele in terms of brand breadth. However, Zwilling's new food processor may take advantage of its core benefit of sharpness.

In line with the above illustration, although a brand with a framed logo may not have advantages from an expansive perceived brand breadth as does the one with an open or incompletely framed logo, the greater accountability may serve as a cue for brand trustworthiness and further benefit the brand 
extension attitudes. Brand trustworthiness could further enhance brand extension acceptance (Reast, 2005; Sheinin and Schmitt, 1994; Wu and Yen, 2007). However, asymmetrical logos were considered less sincere than symmetrical ones (Luffarelli et al., 2019). With the potential asymmetrical nature of incompletely framed logos in the current study, the incompleted frame may arouse the unreliable perception by consumers. Also, drawing upon the insight from the first experiment (which noted the more expansive perceived brand breadth with incompletely framed logos over completely framed ones, whereas the completely framed logo associated with higher accountability than did the incompletely framed logos), our research will narrow its focus to the comparison between completely and incompletely framed logos to examine the trade-off between strong brand trustworthiness and expansive brand breadth. We argue that, although completely framed logos may not broaden the perceived brand breadth as much as incompletely framed logos, the strong sense of trustworthiness could aid completely framed logos to compete with incompletely framed logos in terms of brand extension attitudes. This hypothesis offers a mediation relationship:

H5a. The brand trustworthiness mediates the effect of breaking logo frames on brand extension attitudes.

Furthermore, the above effects may depend on consumers' regulatory focus. As mentioned, prevention-focused people adopt an attitude of vigilance to prevent negative outcomes; whereas promotion-focused people adopt an attitude of eagerness to enable positive outcomes (Higgins, 2009; 2012a). Because extension into dissimilar product categories, namely, a far extension, implies greater risk, people with a prevention focus would favor brand extensions less than those with a promotion focus (Yeo and Park, 2006). When brand extensions belong to complementary product categories, promotion-focused consumers would have a more favorable attitude because of their emphasis on the potential benefits in contrast to the prevention-focused ones (Shine et al., 2007).

The preceding notions imply that prevention-focused people's risk aversion may gratify the effect of brand trustworthiness on brand extension attitudes. It is, thus, expected that although the framed logos may decrease the brand extension attitudes in terms of narrow brand breadth, the brand trustworthiness generated by framed logos could diminish such disadvantages. Meanwhile, the brand trustworthiness should exert a larger influence on prevention over promotion-focused people:

H5b. The mediating effect of brand trustworthiness on breaking logo frames on brand extension attitudes is larger among prevention - than promotion-focused people.

\section{Method of Study 2 \\ Materials}

Four sets of logos used in Study 1 were adopted as the stimuli in this study (marked with \# in Appendix 1). To select the product category of parent brands for each set of logos, participants' free associations in Study 1 were screened. The most highly associated product was selected as the product category of the parent brand. Finally, the product categories of these four sets of chosen logos were, namely, sanitary pads, cookies, shampoo and detergent. Based on the calculation of ontological distance noted in Markman and Gentner (1993), the far extension was selected and defined as the product with the seventh ontological distance to the parent brand. The ontological distance of a pair was represented as the number of nodes in the ontology tree that had to be traversed to get from one to the other.

Meanwhile, the manufacturing difficulty of the extensions was considered (Aaker and Keller, 1990) while stimuli were selected. This consideration follows because if incompletely framed and open logos could persuade consumers that the brand has strong proficiency, such capacity may overcome the manufacturing difficulty. Thus, two difficulty and two easily manufactured extensions were selected for replicates to ensure the effects of logo frames and the regulatory focus might appear on different levels of manufacturing difficulty. Taking an extension's product similarity and manufacturing difficulty into consideration, the pajamas, energy drink, hair dryer and dishwasher were chosen to be the new extensions of the sanitary pads, cookies, shampoo and detergent brands, respectively. For introducing easily manufactured products, the two brand extension scenarios were designed into printed advertisements in which a sanitary pad brand advertised its new pajamas and a cookies brand launched its new energy drink. The other two scenarios of difficultly manufactured extensions involved a shampoo brand, which introduced its hair dryer and a detergent brand, which launched its new dishwasher.

Pretest

A pretest was conducted to confirm that the stimuli represented far extensions and indicated the low vs high manufacturing difficulty; it also checked the logo preference. In total, 82 undergraduate students (39 women and 43 men), with an average age of $19.56(S D=1.09)$, rated the product similarity of the parent brands and the extensions $(1=$ very dissimilar to $7=$ very similar), the manufacturing difficulty of the extended products for the sanitary pads, cookies, shampoo and detergent ( 1 = very easy to $7=$ very difficult; Aaker and Keller, 1990) and logo preference $(1=\mathrm{I}$ dislike the logo very much to $7=\mathrm{I}$ like the logo very much). The results confirmed that the pajamas, energy drink, hair dryer and dishwasher were perceived to be the far (but not impossible) extensions of their parent brands. Compared to the median of the seven-point scale, namely, four, the pajamas, energy drink, hair dryer and dishwasher were dissimilar to the sanitary pads, cookies, shampoo and detergent (pajamas: one-sample $t_{(81)}=3.70, p<0.001$; energy drinks: one-sample $t_{(81)}=3.76, p<0.001$; hair dryer: one-sample $t_{(81)}$ $=2.03, p<0.05$; and dishwasher: one-sample $t_{(81)}=2.38, p<$ $0.05)$, respectively. These four new products were all relatively far extensions. Meanwhile, manufacturing the hair dryer and dishwasher $\left(M_{\text {hair dryer }}=5.28\right.$ and $\left.M_{\text {dishwasher }}=5.17\right)$ was more difficult than manufacturing the pajamas and energy drink $\left(M_{\text {pajamas }}=3.46, M_{\text {energy drink }}=3.61 ; F_{(1,81)}=166.48, p<\right.$ $0.001)$, which indicated the successful manipulation of the manufacturing difficulty. Regarding logo preferences, the results indicated that participants favored the incompletely framed logos to the framed and open logos $\left(M_{\text {incomplete }}=4.53\right.$, $M_{\text {complete }}=3.96$ and $\left.M_{\text {open }}=4.07 ; F_{(2,79)}=3.31, p<0.05\right)$. 


\section{Participants and procedure}

In total, 181 undergraduate students (108 women and 73 men), with an average age of $20.61(S D=2.12)$, participated in this study in exchange for a $€ 2$ reward. They were randomly assigned into the open, incompletely framed or completely framed logo condition to review four brand extension scenarios (an example of which is shown in Appendix 2).

After reviewing the scenarios, participants evaluated the new extensions on six seven-point scales ( $1=$ strongly disagree to $7=$ strongly agree): (1) it is a good idea for the brand to launch this new extension, (2) launching this new extension is a proper move for this brand, (3) the new extension will be popular in the market, (4) I like the new extension, (5) I am willing to recommend this new extension to my friends who need it, and (6) I will purchase this new extension if I need one (Algesheimer et al., 2005; Bruke and Edell, 1989; Klink and Smith, 2001; Park et al., 1991; Sheinin and Schmitt, 1994) (Cronbach's $\alpha=0.91-0.93$, for four extensions).

These scores were then averaged to indicate the brand extension attitude. To examine the mediating role of brand trustworthiness, participants evaluated the two related items ( $1=$ strongly disagree to $7=$ strongly agree): ( 1 ) the brand is trustworthy and (2) the brand offers reliable products (Michell et al., 1998). Finally, participants' regulatory focus was accessed (Haws et al., 2010).

\section{Regulatory focus}

Using the same measurement and grouping process as the previous studies, 82 promotion-focused and 77 preventionfocused people were identified. A total of 22 participants whose difference scores of promotion and prevention focus equaled the median score were excluded from further analysis. The promotion-focused participants had higher promotion scores than prevention-focused people did $\left(M_{\text {promotion }}=5.61 \mathrm{vs}\right.$ $\left.M_{\text {prevention }}=4.77, t_{(157)}=8.41, p<0.001\right)$. The preventionfocused participants had higher prevention scores than promotion-focused people did $\left(M_{\text {promotion }}=4.47\right.$ vs $M_{\text {prevention }}=$ $\left.5.11, t_{(157)}=7.35, p<0.001\right)$.

\section{Results of Study 2}

\section{Brand extension attitudes}

The gender effect was checked first to make sure there were no confounding effects on brand extension attitudes $\left(F_{(1,157)}=\right.$ $0.37, n s$.). A 3 (logo: completely framed, incompletely framed and open) $\times 2$ (regulatory focus: promotion vs prevention) $\times 2$ (manufacturing difficulty: low and high) with two repeated measurements was conducted, in which logo and regulatory focuses were between-subject variables and manufacturing difficulty was a within-subject variable. First of all, not surprisingly, the manufacturing difficulty had no interaction effect with the other two variables. Therefore, the manufacturing difficulty was considered a replication so that a similar effect pattern of the logo frame and regulatory focus should be revealed in both difficultly-made and easily-made extensions. As expected, the main effect of the logo frames was significant $\left(M_{\text {complete }}=4.38, M_{\text {incomplete }}=4.37\right.$ and $M_{\text {open }}=4.85$, $\left.F_{(2,153)}=11.71, p<0.001\right)$. The planned contrasts indicated that participants had more positive attitudes toward the extensions from the brand with an open logo than those with an incompletely framed $\log \left(F_{(1,156)}=15.96, p<0.01\right)$. The better brand extension attitudes were likewise found with open logos than with framed logos $\left(F_{(1,156)}=14.80, p<0.001\right)$. These findings supported $\mathrm{H} 4 \mathrm{a}$ and $\mathrm{H} 4 b$. Another main effect was revealed too. In general, promotion-focused participants had more favorable attitudes toward the extensions than prevention-focused ones $\left(M_{\text {promotion }}=4.64\right.$ vs $M_{\text {prevention }}=4.40$, $\left.F_{(1,153)}=7.11, p<0.01\right)$.

Importantly, the interaction between the logo frame and the regulatory focus was significant $\left(F_{(2,153)}=13.98, p<0.001\right)$. The planned contrasts demonstrated that promotion-focused participants favored the new extensions with an open logo rather than those with a framed logo $\left(M_{\text {open }}=5.24\right.$ vs $M_{\text {complete }}=$ 4.19, $\left.F_{(1,153)}=44.68, p<0.001\right)$. Promotion-focused participants also had the superior brand extension attitude with an open logo than with an incompletely framed logo $\left(M_{\text {open }}=\right.$ 5.24 vs $\left.M_{\text {incomplete }}=4.50, F_{(1,153)}=23.75, p<0.001\right)$. Such effects were absent among prevention-focused participants (open vs completely framed logo: $F_{(1,153)}=0.70, n s$.; open vs incompletely framed logo: $F_{(1,153)}=1.70, n s$.). Furthermore, breaking the logo frames (i.e. completely vs incompletely framed logos) enhanced the positive brand extension attitudes among promotion-focused participants $\left(M_{\text {incomplete }}=4.50\right.$ vs $\left.M_{\text {complete }}=4.19, F_{(1,153)}=3.90, p=0.05\right)$. Contrarily, prevention-focused participants favored the extensions with framed logos more than those with incompletely framed logos $\left(M_{\text {incomplete }}=4.22\right.$ vs $\left.M_{\text {complete }}=4.56, F_{(1,153)}=4.68, p<0.05\right)$. These results confirmed the moderating role of the regulatory focus. Figure 4 demonstrated these findings.

\section{Mediating effect of trustworthiness}

Initially, a GLM with four measurements was conducted to reveal the influence of frame patterns and the regulatory focus on brand trustworthiness. As expected, the significant main effect of breaking logo frames (i.e. the comparison between a complete and incomplete frame) was found $\left(F_{(2,153)}=41.98\right.$, $p<0.001)$. The planned contrast supported the idea that the brand with completely framed logos was more trustworthy than the ones with incompletely framed logos $\left(M_{\text {complete }}=4.26\right.$ vs $\left.M_{\text {incomplete }}=3.65\right)$. As predicted, breaking logo frames decreased prevention-focused participants' evaluation of trustworthiness more than those of promotion-focused participants $\left(F_{(1,153)}=6.76, p<0.05\right)$.

Figure 4 The brand extension attitudes with open, incompletely framed and completely framed logos among all, promotion-focused and prevention-focused participants

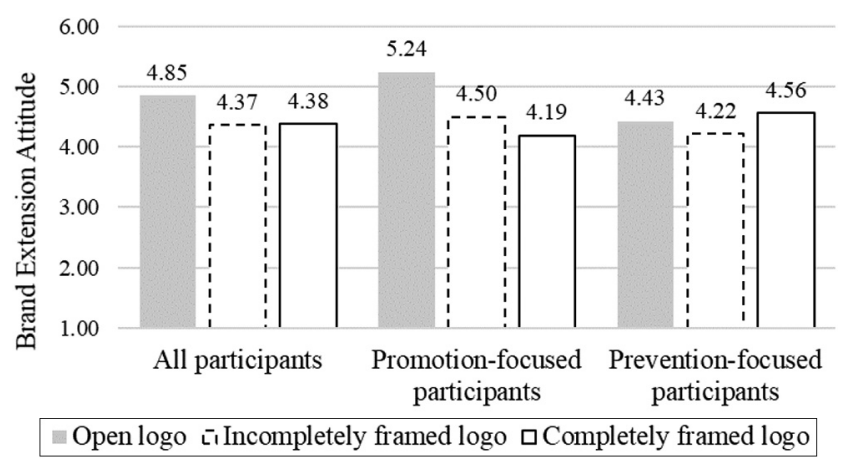


To examine the mediating role of brand trustworthiness in the relationship between breaking logo frames and brand extension attitudes among both the promotion- and prevention-focused consumers, the moderated mediation models with 2,000 bootstrap estimates, as shown in Figure 5, were conducted. The model indicates that brand trustworthiness mediated the effect of breaking logo frames on brand extension attitudes $(E S=-0.40,95$ per cent $\mathrm{CI}=-0.66$ and -0.21 ), which supported $H 5 a$. Further conditional effects noted that breaking the logo frames could directly enhance promotion-focused participants' attitudes toward brand extensions ( $\beta=0.29, t=1.99, p<0.05)$, which may come from the broad perceived brand breadth by incompletely framed logos. Meanwhile, breaking the logo frames decreased the favorable attitudes through brand trustworthiness among promotion-focused participants $(E S=-0.36,95$ per cent $\mathrm{CI}=$ -0.58 and -0.19$)$. Even strong mediation effects on low brand trustworthiness was found among prevention-focused participants $(E S=-0.50 ; 99$ per cent $C I=-1.09$ and -0.15$)$, as $H 5 b$ predicted.

\section{Conclusions and discussions of Study 2}

The results of Study 2 show that an open logo may be beneficial when the brand steps far to a new product category, especially when consumers are promotion focused. Such a promotion focus could be manipulated by marketing appeals via emphasizing ones' dreams and accomplishments (Lee and Aaker, 2004). A brand may synergize marketing efforts with logo identity for its new extensions.

A logo with an incomplete frame has a complicated influence on brand extension attitudes. Paralleling Hagtvedt (2011), incomplete patterns bestow upon a brand an image of innovativeness and proficiency, which broadens the perceived brand breadth, as demonstrated in our first study. The brand extension attitudes may be enhanced via the broad brand image. However, the broken frame also implies a sense of untrustworthiness. These results suggest that an incomplete pattern does not always lead to advantages; these negative effects of untrustworthiness on brand extension attitudes should be counteracted. The pros and cons depend on consumers' regulatory focus. A brand may gain some advantage from an incompletely framed logo via promotionfocused marketing appeals.

It is worth noting that participants in prevention-focus appreciate the trustworthiness associated with a completely framed logo, which has positive impacts on brand extensions. Borrowing the notions regarding "safety products" by Fajardo et al. (2016), a complete logo may be suitable for banks, transportation, medical or health-related products, and welfare organizations. Also, when a brand uses a logo with a complete frame, the brand may further enhance its trustworthy and reliable image for prevention-focused people.

While our results do not consider other consequences of broad vs narrow brand perceptions in the model simultaneously, the findings do highlight opportunities to leverage logo frame designs to brand extension attitudes when introducing products distant from a brand. Collectively, these results extend the previous findings (Cutright, 2012; Fajardo et al., 2016; Hagtvedt, 2011) and bolster the substantive implication in brand management and development.

\section{General discussions}

\section{Comprehensive conclusions and implications}

As marketers attempt to leverage their brands to extend into diverse product categories, issues concerning the product portfolio and perceived fit are critical. Beyond all the determinants of a successful brand extension studied previously, the current research elucidates certain auxiliaries based on the logo frame design. This research responds to Salgado-Montejo et al. (2014, p. 638), who appealed for "further research [...] to help operationalize logo design and provide better tools for brand managers when it comes to choosing, modifying or evaluating the logo of a company or product." Our study provides an easy-to-implement guideline for logo frame designs. In addition, by introducing the passive and active white space, our results could be interpolated into the design guidelines.

Figure 5 The moderating mediated model of Study 2

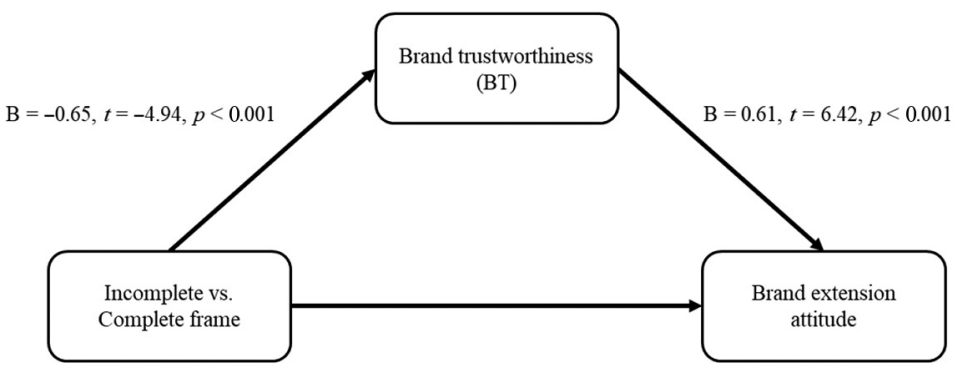

Incomplete vs. Complete frame $\rightarrow$ Brand extension attitude

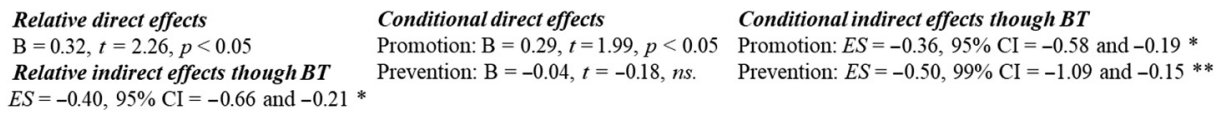

Notes: $\mathrm{ES}=$ mean estimate of effect size; ${ }^{*} p<0.05 ;{ }^{*} p<0.01$; according to the exclusion of zero in $95 \%$ confidence interval after 2,000 bootstrap estimates 
The results of these two studies add to the understanding of how logo frame patterns influence consumers' thinking of a brand's product portfolio. Moreover, the findings shed light on the possible consequences of brand extension strategies. As opposed to investigating logo frame design from a strictly aesthetic point of view, the current studies examined the evolution of a logo frame from its initial product portfolio to its proposed expansion. The current work highlights the individual difference, namely, consumers' regulatory focus, among these effects.

The two studies have shown that removing or breaking a logo frame can broaden the perceived product portfolio and make a positive impact on brand extension strategies. Study 1 demonstrated that consumers could generate greater varieties of product associations with an open logo vs an incompletely framed logo and even more so than a completely framed logo. The supporting evidence of Study 1 is that these various product associations are related to the brand impression, including vivacity, proficiency and accountability based on the open, incomplete, and complete frame. Study 2 was, thus, conducted on the foundation of Study 1's findings and directly applied to far brand extension situations. The results of Study 2 further confirm that an open logo can contribute more to the brand extension attitudes than framed logos do.

This research also illustrated that the effects of logo frames are dependent on receivers' regulatory focus. The positive effect of removing or breaking a logo frame for brand extensions is more profound with promotion-focused than prevention-focused consumers. On the contrary, a brand with a completely framed logo may be limited with new extensions due to the perceived narrow brand breadth, but preventionfocused consumers tend to prefer its trustworthy signification. The moderating effect of the regulatory focus is particularly important on the logos with incomplete frames. Favorable extension attitudes followed an incomplete frame under a promotion focus. The proficiency and vivacity impression generated by the incomplete frame may account for the above effect. However, an incomplete frame had a negative impact on new extension attitudes under a prevention focus via the untrustworthiness impression.

Our first study demonstrated that breaking the logo frame enlarges the perceived brand breadth under a promotion focus, whereas such an effect is eliminated when participants are prevention focused. Therefore, an incompletely framed logo may not benefit the brand extension attitudes under a prevention focus. Further, drawing from Yeo and Park's (2006) equation, brand extension evaluation is determined by hedonic attainment value and perceived risk of that attainment. A brand extension provides an opportunity for consumers to experience the brand in a new product category, which may elicit a positive response such as excitement and pleasure. However, a new extension also brings a risk or uncertainty about product quality. The risk perception would be particularly high when a brand extends to a dissimilar product category. Yeo and Park (2006) showed that promotion and prevention-focused people allocated a great weight to hedonic value and perception of risk, respectively. Paralleling with the above result, our prevention-focused participants may attach greater concerns to brand untrustworthiness and, in turn, evaluate the new extension less favorably than did the promotion-focused participants.

Logo redesign is actually an expensive activity. For example, the UK petroleum group BP spent $£ 136 \mathrm{~m}$ introducing its current sunflower design in 2000 (Caroline and Michael, 2000) and PepsiCo spent $\$ 1 \mathrm{~m}$ to have its logo redesigned (Stampler, 2013), which did not include the cost to educate consumers and to promote the new logo. Brand managers do not make this decision easily. The current study does not take the position of encouraging brand managers to redesign logos frequently. However, brand managers have to consider if their brand logos are updated. Müller et al. (2013) reviewed several real logos for their efforts toward rejuvenation and found that consumers tend to prefer the new ones and rate them as more modern than the previous logos. Once the brand manager decides to rejuvenate the logo or extend the product portfolio, our findings provide a design guideline. At a minimum, these results should lead managers to consider the wisdom in Starbucks' successful case.

\section{Limitations and directions for future research}

Logos may show the brand name alone (e.g. IBM, Intel and Ford) or in combination with a visual symbol (e.g. Starbucks' Siren and McDonald's golden arches). In the latter case, the symbols serve as the actual brand logos, such that the brand names appear as complements alongside the symbols (e.g. Starbucks' logo before 2011) or may even be dropped altogether in favor of the visual sign (e.g. Starbucks' current logo). The current study only assesses whether crafting logo frame patterns along with the symbols has a differential influence on providing consumers broad or narrow brand breadth with particular impressions, and in turn, impacts consumers' brand extension attitudes. Moreover, previous research has indicated that consumers responded differently toward image-based logos vs text-based logos (Morgan et al., 2017). Park et al. (2013) noted that, compared to brand-namebased logos, visual-symbol-based logos effectively express consumers' self-identity. Extending from their findings, the highly self-involved factor, regulatory focus, may have a stronger influence on symbol-based logos than name-based logos. Future researchers are invited to explore the effect of frame patterns on visual-symbol-based and brand-name-based logos.

The results of this research support Starbucks' announcement that removing the logo frame and "Starbucks Coffee" to free the Siren was a signal of its new strategic extension decision. With numerous real cases of removing or adding frames, such as Cadillac, Citroën, Dodge and Lexus, it would be interesting to evaluate the transformation of the brand image before and after the logo redesign based on the suggestions of this research for future study.

The real cases of logo redesign further introduce a limitation of the current research. To control the interference, we used fictitious brands and logos in experiments. It is suggested to future researchers to use real logos and regular consumers to enhance the external validity and minimize the bias of sample distribution. It is possible that loyal consumers may strongly attach to the original logo, but hardly accept a new design (Peterson et al., 2015). This possibility implies that loyal consumers may not appreciate the freedom impression, but 
decrease the trustworthy feeling, via removing a logo frame. If researchers in the future intend to investigate the effects of logo frames on real logos, consumers' emotions and attachment toward the original logo has to be taken under consideration.

A logo frame revolution may also raise the risk of consumer anxiety of the "change" (Peterson et al., 2015). While the research is mute on this topic, one could envision scenarios in which a brand removes or breaks the frame on its logo when launching a new extension unintentionally diminishes the loyalty of its consumer base to that brand. Hopefully, this paper will simulate additional analytical and empirical research in this domain.

The regulatory focus was presumed as the participants' chronic orientation in the current study. The orientation of the regulatory focus could be a further issue. While measuring participants' regulatory focus is a relatively straightforward technique, it is not practical enough in the real market environment. Future investigations may follow this logo frame design but manipulate the promotion and prevention focus via marketing cues concerning innovativeness or trustworthiness. The results should be able to illustrate if the logo frame could affect the fit through certain activations of a regulatory focus and provide a practical foundation for using the regulatory focus in marketing appeals to fit with the logo frame.

Finally, the effectiveness of a logo design likely depends on multiple design features of the logo, such as shape, color, proportion and frame. A multiple interaction analysis of frame patterns and specific logo features is not in the scope of the present study. One may envision an investigation, for example, as to whether breaking the circular frame of a logo, which is perceived as highly customer sensitive (Jiang et al., 2016), decreases brand trustworthiness and influences brand extension attitudes more than does an angular frame.

\section{References}

Aaker, D.A. and Keller, K.L. (1990), "Consumer evaluations of Brand extensions”, fournal of Marketing, Vol. 54 No. 1, pp. 27-41.

Aaker, J.L. (1997), "Dimensions of brand personality”, fournal of Marketing Research, Vol. 34 No. 3, pp. 347-356.

Aaker, J.L. and Lee, A.Y. (2006), "Understanding regulatory fit", fournal of Marketing Research, Vol. 43 No. 1, pp. 15-19.

Algesheimer, R., Dholakia, U.M. and Herrmann, A. (2005), "The social influence of brand community: evidence from European car clubs", fournal of Marketing, Vol. 69 No. 3, pp. 19-34.

Arora, R. and Stoner, C. (2009), "A mixed method approach to understanding brand personality", The Fournal of Product \& Brand Management, Vol. 18 No. 4, pp. 272-283.

Avnet, T. and Higgins, E.T. (2006), "Response to comments on "how regulatory fit affects value in consumer choices and opinions", fournal of Marketing Research, Vol. 43 No. 1, pp. 24-27.

Baxter, S.M. and Ilicic, J. (2018), "May the force drag your dynamic logo: the brand work-energy effect", International fournal of Research in Marketing, 3 April.
Boush, D.M. and Loken, B. (1991), "A process-tracing study of Brand extension evaluation", Fournal of Marketing Research, Vol. 28 No. 1, pp. 16-28.

Bottomley, P.A. and Holden, S.J.S. (2001), "Do we really know how consumers evaluate brand extensions? Empirical generalizations based on secondary analysis of eight studies", Fournal of Marketing Research, Vol. 38 No. 4, pp. 494-500.

Brasel, S.A. and Hagtvedt, H. (2016), "Living brands: consumer responses to animated brand logos", fournal of the Academy of Marketing Science, Vol. 44 No. 5, pp. 639-653.

Bresciani, S. and Paolo, D.P. (2017), "New brand logo design: customers' preference for brand name and icon", fournal of Brand Management, Vol. 24 No. 5, pp. 375-390.

Bruke, M.C. and Edell, J.A. (1989), "The impact of feelings on ad-based affect and cognition", fournal of Marketing Research, Vol. 26, pp. 69-83.

Buil, I., de Chernatony, L. and Hem, L.F. (2009), "Brand extension strategies: perceived fit, brand type, and culture influences", European Fournal of Marketing, Vol. 43 Nos 11/12, pp. 1300-1324.

Cannold, J. (2011), "Starbucks buys juice maker evolution fresh", Business, 11 November, CNN, New York, NY.

Caroline, D. and Michael, P. (2000), "BP attacked over $£ 136 \mathrm{~m}$ logo as petrol prices soar", The Telegraph, 25 July, Telegraph Media Group.

Cutright, K.M. (2012), "The beauty of boundaries: when and why we seek structure in consumption", fournal of Consumer Research, Vol. 38 No. 5, pp. 775-790.

Dawar, N. (1996), "Extensions of broad brands: the role of retrieval in evaluations of fit", fournal of Consumer Psychology, Vol. 5 No. 2, pp. 189-207.

Dotzel, T., Shankar, V. and Berry, L.L. (2013), "Service innovativeness and firm value", fournal of Marketing Research, Vol. 50 No. 2, pp. 259-276.

Einstein, G.O. and Hunt, R.R. (1980), "Levels of processing and organization: additive effects of individual-item and relational processing", fournal of Experimental Psychology: Human Learning and Memory, Vol. 6 No. 5, pp. 588-598.

Fajardo, T.M., Zhang, J. and Tsiros, M. (2016), "The contingent nature of the symbolic associations of visual design elements: the case of Brand logo frames", fournal of Consumer Research, Vol. 43 No. 4, pp. 549-566.

Foroudi, P., Melewar, T.C. and Gupta, S. (2014), "Linking corporate logo, corporate image, and reputation: an examination of consumer perceptions in the financial setting", Fournal of Business Research, Vol. 67 No. 11, pp. 2269-2281.

Fox, E.J. (2012), "Teavana up 50\% on Starbucks acquisition", CNN Money, 14 November, The Time Warner Company, New York, NY.

GS1 (2016), "GS1: general specifications, version 16", available at: www.gs 1.org/standards/id-keys/gtin

Hagtvedt, H. (2011), "The impact of incomplete typeface logos on perceptions of the firm", Fournal of Marketing, Vol. 75 No. 4, pp. 86-93.

Haws, K.L., Dholakia, U.M. and Bearden, W.O. (2010), "An assessment of chronic regulatory focus measures", Fournal of Marketing Research, Vol. 47 No. 5, pp. 967-982. 
Henderson, P.W. and Cote, J.A. (1998), "Guidelines for selecting or modifying logos", fournal of Marketing, Vol. 62 No. 2, pp. 14-30.

Higgins, E.T. (1997), "Beyond pleasure and pain", The American Psychologist, Vol. 52 No. 12, pp. 1280-1300.

Higgins, E.T. (2009), "Regulatory fit in the goal-pursuit process", The Psychology of Goals, Guilford Press; US, New York, NY, pp. 505-533.

Higgins, E.T. (2012a), "Motivational fit", Cognitive Consistency: A Fundamental Principle in Social Cognition, Guilford Press; US, New York, NY, pp. 132-153.

Higgins, E.T. (2012b), "Regulatory focus theory", Handbook of Theories of Social Psychology, Vol. 1, Sage Publications Ltd, Thousand Oaks, CA, pp. 483-504.

Higgins, E.T., Idson, L.C., Freitas, A.L., Spiegel, S. and Molden, D.C. (2003), “Transfer of value from fit", fournal of Personality and Social Psychology, Vol. 84 No. 6, pp. 1140-1153.

Huttenlocher, J., Hedges, L.V. and Duncan, S. (1991), "Categories and particulars: prototype effects in estimating spatial location", Psychological Review, Vol. 98 No. 3, pp. 352-376.

Hynes, N. (2009), "Colour and meaning in corporate logos: an empirical study", Fournal of Brand Management, Vol. 16 No. 8, pp. 545-555.

Isidore, C. (2012), "Starbucks opens its first juice bar", CNN Money, 19 March, 2012, New York, NY, The Time Warner Company.

Jiang, Y., Gorn, G.J., Galli, M. and Chattopadhyay, A. (2016), "Does your company have the right logo? How and why circular- and angular-logo shapes influence Brand attribute judgments", Fournal of Consumer Research, Vol. 42 No. 5, pp. 709-726.

Jin, C., Yoon, M. and Lee, J. (2019), "The influence of brand color identity on brand association and loyalty", Fournal of Product \& Brand Management, Vol. 28 No. 1, pp. 50-62.

Kavilanz, P. (2011), "Starbucks unveils a new logo", CNN Money, 5 January, The Time Warner Company, New York, NY.

Keller, K.L. and Aaker, D.A. (1992), "The effects of sequential introduction of brand extensions", Fournal of Marketing Research, Vol. 29 No. 2, pp. 35-50.

Klink, R.R. and Smith, D.C. (2001), "Threats to the external validity of brand extension research", fournal of Marketing Research, Vol. 38 No. 3, pp. 326-335.

Lee, A.Y. and Aaker, J.L. (2004), "Bringing the frame into focus: the influence of regulatory fit on processing fluency and persuasion", Fournal of Personality and Social Psychology, Vol. 86 No. 2, pp. 205-218.

Luffarelli, J., Stamatogiannakis, A. and Yang, H. (2019), "The visual asymmetry effect: an interplay of logo design and Brand personality on Brand equity", fournal of Marketing Research, Vol. 56 No. 1, pp. 89-103.

Machado, J.C., Leonor Vacas, D.C., Anna, T. and Patrício, C. (2015), "Brand logo design: examining consumer response to naturalness", Fournal of Product E Brand Management, Vol. 24 No. 1, pp. 78-87.

Markman, A.B. and Gentner, D. (1993), "Structural alignment during similarity comparisons", Cognitive Psychology, Vol. 25 No. 4, pp. 431-467.
Meggs, P.B. and Purvis, A.W. (2011), Meggs' History of Graphic Design, John Wiley \& Sons.

Meyers-Levy, J. (1991), "Elaborating on elaboration: the distinction between relational and item-specific elaboration", fournal of Consumer Research, Vol. 18 No. 3, pp. 358-367.

Meyers-Levy, J. and Zhu, R. (2007), “The influence of ceiling height: the effect of priming on the type of processing that people use", fournal of Consumer Research, Vol. 34 No. 2, pp. 174-186.

Meyvis, T. and Janiszewski, C. (2004), "When are broader brands stronger brands? An accessibility perspective on the success of Brand extensions", fournal of Consumer Research, Vol. 31 No. 2, pp. 346-357.

Michell, P., Reast, J. and Lynch, J. (1998), "Exploring the foundations of trust", Fournal of Marketing Management, Vol. 14 Nos 1/3, pp. 159-172.

Morgan, S.C., Fajardo, T. and Townsend, C. (2017), "Say it or show it: logo aesthetics and consumer-brand relationship development", Annual Conference, Association for Consumer Research, San Diego, $C A$.

Müller, B., Kocher, B. and Crettaz, A. (2013), "The effects of visual rejuvenation through Brand logos”, Fournal of Business Research, Vol. 66 No. 1, pp. 82-88.

Narelle, P., Michael, E. and Colin, J. (2007), "Aesthetic theory and logo design: examining consumer response to proportion across cultures", International Marketing Review, Vol. 24 No. 4, pp. 457-473.

Park, C.W., Eisingerich, A.B., Pol, G. and Park, J.W. (2013), "The role of Brand logos in firm performance", fournal of Business Research, Vol. 66 No. 2, pp. 180-187.

Park, C.W., Milberg, S. and Lawson, R. (1991), "Evaluation of Brand extensions: the role of product feature similarity and brand concept consistency", Fournal of Consumer Research, Vol. 18 No. 2, pp. 185-193.

Peterson, M., AlShebil, S. and Bishop, M. (2015), "Cognitive and emotional processing of Brand logo changes", Fournal of Product \& Brand Management, Vol. 24 No. 7, pp. 745-757.

Rahinel, R. and Nelson, N.M. (2016), "When Brand logos describe the environment: design instability and the utility of safety-oriented products", Fournal of Consumer Research, Vol. 43 No. 3, pp. 478-496.

Reast, J.D. (2005), "Brand trust and brand extension acceptance: the relationship", Fournal of Product E Brand Management, Vol. 14 No. 1, pp. 4-13.

Salgado-Montejo, A., Velasco, C., Olier, J.S., Alvarado, J. and Spence, C. (2014), "Love for logos: evaluating the congruency between Brand symbols and typefaces and their relation to emotional words", fournal of Brand Management, Vol. 21 Nos 7/8, pp. 635-649.

Sharma, N. and Varki, S. (2018), "Active white space (AWS) in logo designs: effects on logo evaluations and brand communication", fournal of Advertising, Vol. 47 No. 3, pp. 270-281.

Sheinin, D.A. and Schmitt, B.H. (1994), "Extending brands with new product concepts: the role of category attribute congruity, brand affect, and Brand breadth", Fournal of Business Research, Vol. 31 No. 1, pp. 1-10. 
Shine, B.C., Park, J. and Wyer Jr, R.S. (2007), "Brand synergy effects in multiple Brand extensions", fournal of Marketing Research, Vol. 44 No. 4, pp. 663-670.

Sichtmann, C. and Diamantopoulos, A. (2013), "The impact of perceived Brand globalness, Brand origin image, and brand origin-extension fit on Brand extension success", Fournal of the Academy of Marketing Science, Vol. 41 No. 5, pp. 567-585.

Stampler, L. (2013), "How much the world's most iconic logos cost companies to design them”, Business Insider, 26 March, Insider Inc.

Tadena, N. (2012), "Starbucks to buy bay bread for $\$ 100$ million", The Wall Street fournal, 4 June, Dow Jones and Company, New York, NY.

Turnbull, C. (2011), "Using white space (or negative space) in your designs", available at: http://webdesign.tutsplus.com/ articles/using-white-space-or-negative-space-inyour-designswebdesign-3401 (accessed 1 January 2019).

Van Grinsven, B. and Das, E. (2016), "Logo design in marketing communications: brand logo complexity moderates exposure effects on Brand recognition and Brand attitude", Fournal of Marketing Communications, Vol. 22 No. 3, pp. 256-270.

Wilder, D.A. (1986), "Social categorization: Implications for creation and reduction of intergroup bias", in Berkowitz, L. (Ed.) Advances in Experimental Social Psychology, Academic Press, pp. 291-355.
Wu, C. and Yen, Y.C. (2007), "How the strength of parent Brand associations influence the interaction effects of Brand breadth and product similarity with Brand extension evaluations", Fournal of Product \& Brand Management, Vol. 16 No. 5, pp. 334-341.

Yeo, J. and Park, J. (2006), "Effects of parent-extension similarity and self regulatory focus on evaluations of Brand extensions", fournal of Consumer Psychology, Vol. 16 No. 3, pp. 272-282.

Völckner, F. and Sattler, H. (2006), "Drivers of Brand extension success", fournal of Marketing, Vol. 70 No. 2, pp. 18-34.

Zhong, K., Wang, H. and Zhang, C. (2018), "Brand elongation effect: the impact of logo shape on assessment of products' temporal property and Brand evaluation", Nankai Business Review International, Vol. 9 No. 1, pp. 59-77.

\section{Further reading}

Kimball, M.A. (2013), "Visual design principles: an empirical study of design lore", Fournal of Technical Writing and Communication, Vol. 43 No. 1, pp. 3-41.

Pracejus, J.W., Olsen, G.D. and O'Guinn, T.C. (2006), “How nothing became something: white space, rhetoric, history, and meaning", fournal of Consumer Research, Vol. 33 No. 1, pp. 82-90. 


\section{Appendix 1. Logo stimuli used in Study 1}

Completely framed logos
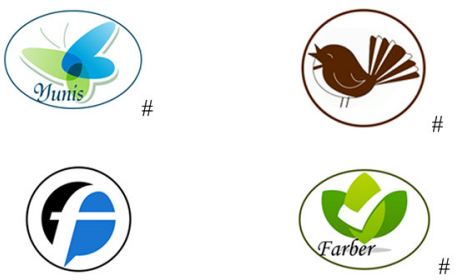

Incompletely framed logos
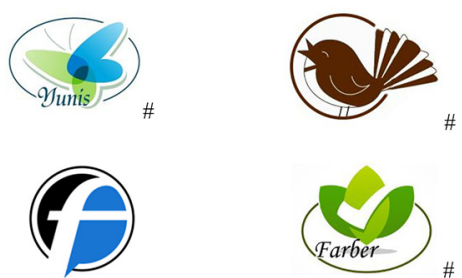
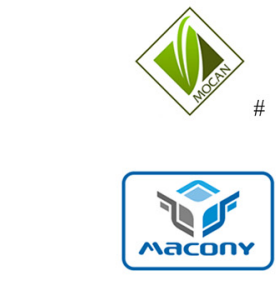

Open logos
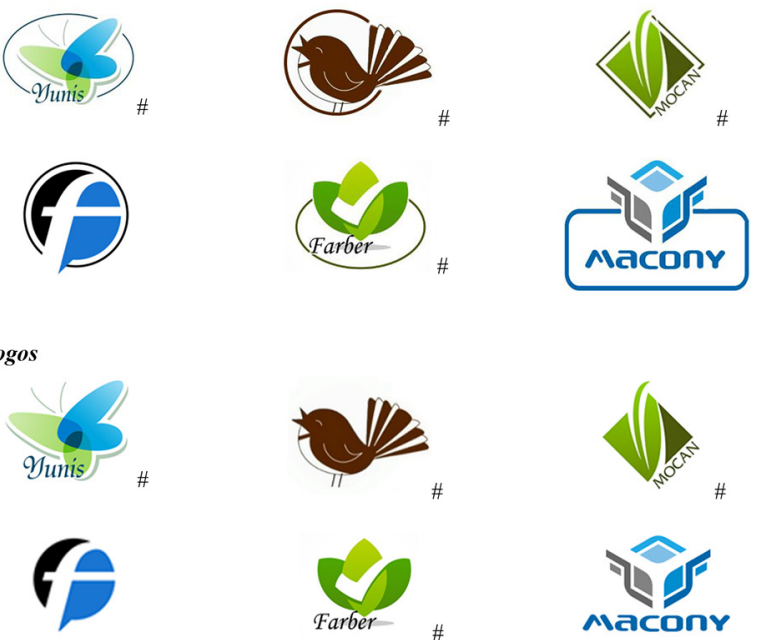

\section{About the authors}

Yu-Shan Athena Chen is an Assistant Professor at the Industrial Design Department of Eindhoven University of Technology (TU/e) in The Netherlands. Her research focuses on brand management and consumers' responses to commercial and industrial designs, with specific interests in logo, packaging, and computer-human-interaction. Yu-Shan Athena Chen is the corresponding author and can be contacted at: y.s.chen@tue.nl

Lien-Ti Bei is a Distinguished Professor in the Department of Business Administration at National Chengchi University (NCCU) in Taiwan. She is also responsible for the Sinyi Research and Development Center for Business Ethics at NCCU. Her research interests include consumer behavior and brand management. She has published her research in international journals and Chinese journals in marketing and consumer behavior.

Note: The four sets of logos marked with \# were also used in

Study 2

\section{Appendix 2. An example of brand extension scenarios used in Study 2}

Completely framed logo condition

Note: The Chinese sentence means "Cookie brand Bourbon will launch a new energy drink" 